\title{
Letras premiadas y no mencionadas en las Crónicas del Festival Internacional del Cante de las Minas
}

Domingo Giménez Cánovas

Universidad de Murcia

\section{Resumen}

Enviado: $13-10-2020$

Aceptado: $30-11-2020$

El Festival del Cante de las Minas de La Unión convocó concursos de letras de distintas modalidades entre 1971 y 2004. No hay una publicación específica dedicada a estos concursos, y la relación más detallada sobre ellos se puede encontrar en las Crónicas del Festival Internacional del Cante de las Minas, con cinco ediciones (la última en 2010). Las sucesivas ediciones contienen algunas lagunas en lo que se refiere a los premios de letras, con algunas de estas o de los autores ausentes o erróneas. En este trabajo se completa la información sobre los premios de letras que aparece errónea o incompleta.

Palabras clave: cante de las minas; letras flamencas; mineras.

\section{Abstract}

The "Festival del Cante de las Minas" in La Unión included between 1971 and 2004 lyric contests of different modalities. There is no publication dedicated to these contests, and the most detailed relation is in the Crónicas del Festival Internacional del Cante de las Minas, with five editions (the last one in 2010). The successive editions contain some mistakes, with some of the lyrics or authors absent or wrong. In this work we complete the information that appears erroneous or incomplete. 


\section{Introducción}

Se admite generalmente que la letra flamenca juega un papel quizás secundario en el cante, y que es el cantaor muchas veces el padre de la letra que interpreta, o al menos el que le da con su toque alma a esta. Ya lo dice Enrique Hernández-Luike (el ganador de más premios de letras en el Festival del Cante de las Minas) refiriéndose a una minera suya cantada por Pencho Cros:
Una minera escribí, la premiaron en La Unión. ¡Qué gran emoción sentí! Me la cantó Pencho Cros y entonces la comprendí.

Y lo expresa magistralmente Manuel Machado en su conocida copla:

$$
\begin{aligned}
& \text { Hasta que el pueblo las canta } \\
& \text { las coplas coplas no son } \\
& \text { y cuando las canta el pueblo } \\
& \text { ya nadie sabe su autor. }
\end{aligned}
$$

Por este motivo, y porque la letra y el cante surgen del pueblo, muchas de las letras del flamenco son anónimas o populares, o no se cae en mencionar a los letristas cuando se habla de ellas. Así, podemos ver en el interesante y ameno trabajo de José Luis Blanco, José Luis Rodríguez y Francisco Robles (Blanco, Rodríguez, Robles, 2004), que usualmente no se atribuyen las letras a sus autores. Así pasa, por ejemplo, cuando incluyen sin mencionar a su autor una letra del poeta cartagenero afincado en Albacete José Jorquera Manzanares, la que empieza "En la mina se escuchó", con la que ganó el premio de letras de mineras en el Festival de La Unión en 1980. Lo mismo ocurre en los libros (más centrados en el aspecto musical pero con un listado y análisis de algunas de las letras que se cantan) de José Francisco Ortega sobre los cantes de las minas (Ortega, 2017) y del mismo autor con Luis Soler, Rafael Ruiz y Antonio Gómez sobre la malagueña (Ortega, Soler, Ruiz, Gómez, 2019), en los que se nombra a los cantaores que interpretan las letras, pero solo en contadas ocasiones se menciona a los letristas. Por ejemplo, en el primero de estos libros solo hemos encontrado 


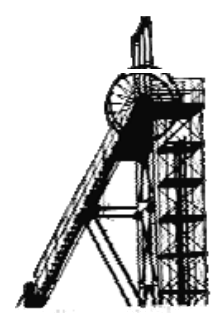

referencias a dos ellos, ambos ganadores en La Unión (Enrique Hernández y Antonio Murciano), pero se incluyen algunas letras de las allí premiadas sin indicar el autor: al menos la mencionada de José Jorquera y la popular minera del unionense Basilio Martínez Vera de primer verso "Se oye un grito en el rundío", con la que ganó el premio de nueva letra cantada en 1972.

A pesar de esta ignorancia generalizada de sus autores, las letras flamencas son en muchos casos ejemplos brillantes del quehacer poético, tal como indica José Martínez (Martínez, 2005): «El cante flamenco tiene una dimensión literaria y poética a la que normalmente se le ha prestado muy poca atención», que menciona también que a partir de mitad del siglo XIX el flamenco empezó a recibir la atención de poetas y literatos. En esto coincide con Blanco, Rodríguez y Robles, que al final de su libro antes mencionado realizan un repaso por una serie de reconocidos escritores (Bécquer, Antonio Machado, Manuel Machado, Juan Ramón Jiménez, Lorca, Alberti, Baroja, Cela, Bergamín, etc.) y analizan la relación de su poesía con el flamenco.

Siendo conscientes de la importancia de las letras en el flamenco y de la dimensión poética que estas pueden tener, se han venido convocando premios para promover la creación de letras de calidad. Ya en 1995 Luis Antonio Utrera (Utrera, 1995) menciona como principales convocatorias las del Festival del Cante de las Minas, la de la Asociación Andaluza Hijos de Almáchar de Baracaldo y "La Torre del Cante" en Alhaurín de la Torre; pero también encontramos otra serie de convocatorias más esporádicas, más recientes o con temática más restringida: el Concurso Nacional de Tarantas de Linares, el de letras flamencas del Ateneo de Córdoba, el de poesías y letras flamencas de Puerto Real, el de letras de fandangos "Paco Toronjo y Alosno", el concurso "La Fragua de La Isla", el "Francisco Moreno Galván", el concurso de letras de cartageneras "Ginés Jorquera" (letrista cartagenero muy ligado al Festival de La Unión como organizador y jurado, que ha fallecido el 31 de mayo de 2020), etc.

El Festival del Cante de las Minas (de ahora en adelante el Festival) lleva celebrándose desde 1961, con inclusión de premios de letras de distinto tipo 
entre las ediciones de 1971 y 2004.

Ya en 1982 María Cegarra Salcedo expresaba su deseo de que se recopilaran las letras ganadoras de estos concursos: «Es posible que las letras premiadas formen, en su día, un pequeño folleto, para recuerdo y deleite de los que las aman» (del artículo "Cita con el cante", periódico Línea de 19 de agosto de 1982).

La mayoría de estas letras se pueden encontrar en las Crónicas del Festival Internacional del Cante de las Minas (en adelante las Crónicas), con un total de cinco ediciones. Estas Crónicas fueron recopiladas hasta 2002 por Asensio Sáez, y continuadas a partir de 2003 en las dos últimas ediciones por José Alfonso Pérez (Sáez, Pérez, 2010). Las sucesivas ediciones incluyen algunos errores y faltas en los apartados dedicados a los premios de letras. Por otro lado, Enrique Hernández-Luike traslada de las Crónicas las letras premiadas en el Festival a la segunda versión de su Carpeta de Pencho Cros (Hernández, 2015), y toma también algunos de los comentarios de Asensio Sáez, con lo que en su publicación no corrige los fallos mencionados. Por último, un listado de las letras de mineras premiadas entre 1974 y 1990 aparece en la Memoria del Festival de 1991 (Festival, 1991), que no contiene las letras premiadas de otros cantes, con lo que tampoco sirve como recopilación de los premios de todas las ediciones (hasta 2004) y de las diferentes modalidades (nuevas letras cantadas, de 1971 a 1973, y mineras y otros cantes, entre 1974 y 2004).

El objetivo principal de este trabajo es completar la información que sobre los concursos de letras del Festival se encuentra en las Crónicas, desambiguando algunos errores, con lo que se pueda tener la información suficiente para/generar el listado completo y fehaciente de autores y letras galardonados.

La fuente principal de información debería haber sido el archivo de La Unión, pero este permanece cerrado por las restricciones por el coronavirus y por no haber nadie a su cargo desde la muerte de su archivero Paco Ródenas en 2018. La información hubo que buscarla en la mayoría de los casos en internet 


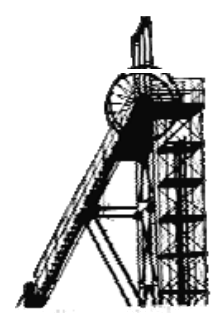

(el trabajo se comenzó durante el periodo de confinamiento por coronavirus), no siendo sencilla de localizar en algunas ocasiones, por haber pasado bastante tiempo desde los correspondientes premios, con lo que algunos de los premiados ya habían fallecido o tienen una actividad muy reducida en los medios digitales. Más adelante, y una vez relajadas las condiciones de confinamiento, se hicieron búsquedas en bibliotecas y archivos, y entrevistas personales, todas ellas dificultadas por las restricciones para evitar la difusión del virus.

En el apartado siguiente se da una primera visión general de los años en los que se han encontrado errores o ausencias y del tipo de estos, y a continuación se incluye por cada año la información correcta cuando esta era errónea o se completa la incompleta. De esta manera se añaden algunas letras y autores que no aparecen en las Crónicas, y se aclaran algunas imprecisiones que aparecen en sus sucesivas ediciones (cinco).

Finalmente, se muestra un resumen de datos sobre las letras y los autores premiados, y se indican algunos datos por completar y posibles extensiones del estudio.

\section{Información completada por años}

En la tabla 1 se indica, por cada año con información por completar y para los dos premios de letras (el de mineras, "Andrés Cegarra Salcedo", y el de otros cantes, "Tertulia Literaria Mesa-Café"), si la correspondiente letra o autor falta, está incompleta o errónea.

Vemos que de las 34 ediciones con premios de letras identificamos datos imprecisos o incompletos en 15 de ellas, lo que supone aproximadamente un $44 \%$. Encontramos algún error en el nombre de los autores premiados, y letras que están incompletas, y en otros casos falta toda la información sobre quién es el autor, o está ausente la letra, o directamente no se mencionan estos premios (ediciones de 2003 y 2004). La información de los años 1994 y 1999 se repite, y corresponde en realidad a 1999. 
Tabla 1. Datos incompletos o erróneos identificados en las

Crónicas del Festival Internacional del Cante de las Minas

\begin{tabular}{|ccccc|}
\hline Año & Autor mineras & Letra mineras & Autor otras & Letra otras \\
\hline 1984 & & & Incompleta \\
\hline 1985 & & & Incompleta \\
\hline 1986 & & Error & Incompleta \\
\hline 1989 & Falta & Error & Falta \\
\hline 1992 & Incompleta & & Incompleta \\
\hline 1993 & Error & Error & Error \\
\hline 1994 & & & Incompleta \\
\hline 1995 & & & & Incompleta \\
\hline 1996 & & & & Incompleta \\
\hline 1997 & & & Falta & Incompleta \\
\hline 1998 & & & & Incompleta \\
\hline 1999 & Error & & & Falta \\
\hline 2000 & & & & \\
\hline 2001 & & Falta & & Falta \\
\hline 2003 & & & & \\
\hline 2004 & & & & \\
\hline
\end{tabular}

Para algunas letras, Asensio Sáez indica de forma explícita en las Crónicas que no se incluyen completas, y otras veces parece indicar esto de forma implícita, con puntos suspensivos al principio o el final o líneas entre algunos versos. Otras veces no se incluye la letra completa quizás por error, y en algunos casos ni siquiera en el acta del jurado aparece la letra completa remitida por el autor, lo que no sabemos si el jurado hace de forma consciente, seleccionando únicamente los versos que considera de mayor calidad para optar al premio.

Se comenta y completa a continuación la información para cada uno de estos años. Incluimos las letras en la forma más completa en que las hemos 


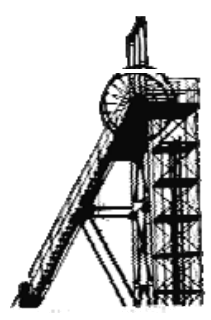

encontrado, recurriendo directamente a los autores o a los documentos que enviaron al concurso, o al acta del jurado, o a la prensa de la época, o a internet.

1984

Carlos Fuentes Peñafiel (Balsicas, Torre-Pacheco, Murcia 1933-2009) gana el premio de letras mineras, y Jacobo Meléndez Martínez (Córdoba 1928-2020) el premio de otras letras.

Jacobo Meléndez recibió también el premio de letras mineras en 1988, 1992, 1993 y 1999. Se le premian en 1984 una serie de soleares, de las que en $L a$ Verdad de 11 de agosto se muestran las siguientes cuatro, aunque las Crónicas no incluyen la segunda:

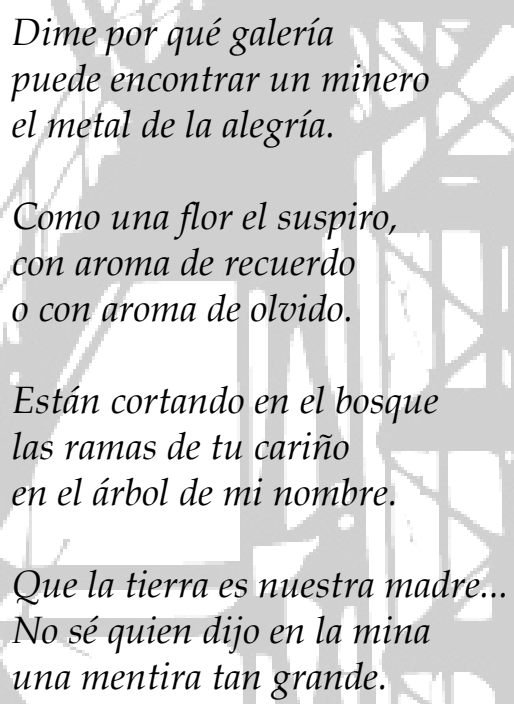

\section{5}

Un mismo autor es el ganador de los dos premios, Enrique HernándezLuike (Huelva 1928), que ganaría muchos otros premios de letras en el Festival: mineras en 1985 y 1992, y otras letras en 1985, 1986, 1987, 1988 y 1990; y que se convirtió a la postre en el autor más premiado.

En las Crónicas se dice que el premio de otras letras corresponde a una colección de tientos, fandangos, alegrías y serranas, y que debido a su longitud se incluye solo la serrana siguiente, con los puntos suspensivos, que sugieren 
texto antes y después de los versos que se muestran:

$$
\begin{aligned}
& \text {... A la luna la pongo } \\
& \text { donde yo quiero, } \\
& \text { cuando trota conmigo } \\
& \text { por el sendero. } \\
& \text { Siempre la sigo, } \\
& \text { pero si yo me paro } \\
& \text { para conmigo... }
\end{aligned}
$$

Encontramos en la página de poemas de Enrique Hernández-Luike (www.luike.com/fundacion-luike/poemas-de-luike/) estos versos con una continuación, con el título de "Livianas de Curro Lucena", por lo que inicialmente pensamos que juntas formaban la letra que ganó en este año. Por otro lado, en los programas del Festival se menciona como ganadora en 1985 únicamente a esta letra de serrana, y se incluyen las "Livianas de Curro Lucena" dentro de las letras ganadoras el siguiente año. Así las cosas, parece ser que las livianas corresponden a la edición de 1986.

Hemos localizado también unas letras de tientos, fandangos y alegrías en un documento de la edición de 1987 del Festival con las bases del premio de cante "Pencho Cros", que iba destinado a «la mejor interpretación de una de las letras premiadas en el Concurso de Letras de este Festival durante los años 1985 y 1986». El autor de todas estas letras es Enrique Hernández-Luike, que patrocina el premio. En el documento se incluye, junto con la serrana anterior y con las dos letras premiadas en 1986, unas letras de tientos, fandangos y alegrías, que no se indica claramente a qué corresponden, pero suponemos son las de esta edición, por lo que las incluimos aquí:

¡Hay que ver como diluvia!

Todo el mundo se alborota, que no te importe la lluvia yo tengo un arca que flota.

Un ramito de oliva verde

blanca paloma

lleva en el pico.

No quiero que te acuerdes, 
sentrañas mías,

cuando ha llovido.

Que toma, toma, tomate que toma la tomatera, que no haces un disparate, tonta de remate, volviendo a mi vera.

Todos los bichos del mundo en el arca se han subido, cada uno con su pareja, tú de pareja conmigo.

Y eso lo dijo Noé sentado en la mesa tomando café.

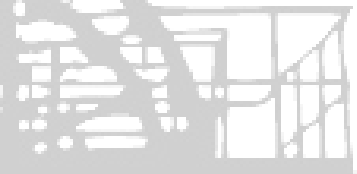
(Tientos de Noé)

Me diste un beso en la boca: jel gordo en la lotería! Ahora espero cada día y el segundo no me toca: ¡qué mala suerte la mía!

Yo no te olvido, mujer, $y$ en ti pienso en alta mar: tú me enseñaste a querer, pero aprender a olvidar ¡qué difícil debe ser!

En Huelva tengo un secreto que no se lo digo a nadie, un secreto tan secreto que toíto el mundo sabe: ¡qué mundo tan indiscreto!

Tu sombra pisé al cruzar por la plaza de las Monjas y tuve que tropezar: tú tienes muy mala sombra con esa forma de andar.

\section{(Fandangos)}

Tu mujer es una santa, la tienes que respetar: yo no sé cómo te aguanta sin subirte en el altar. 
Que viva Palomares con sus palomas, que viva, viva Paco el de la Bomba.

No te lavaras la cara con el agua de mi fuente, que se intoxica la cabra, y se le corta la leche.

En tu pozo no pico, primita mía, que ya llevo picando toda la vida.

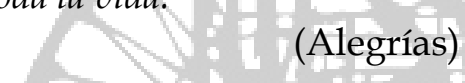

1986

El premio de letras mineras queda desierto, y el de otras letras va a parar de nuevo a Enrique Hernández-Luike, que en las Crónicas se indica que este año gana con las siguientes seguiriyas:

El aire me falta para respirar.

Yo aspiraba tan solo tu aliento

y tú ya no estás.

Eras tan bonita como el mismo sol. En este mundo pa ti no había sitio y te llevó Dios.

Que me voy pa Armenia que me quiero ir donde no vea tanticos recuerdos que me hablen de ti.

Cabezo Rajao, Casa del Piñón y aquel Mercao donde pregonabas quiero olvidar yo.

Pero, tal como hemos mencionado para la edición anterior, las siguientes livianas con serrana (que en la página de Enrique Hernández se nombran como "Livianas de Curro Lucena") aparecen en el programa del Festival (me lo 


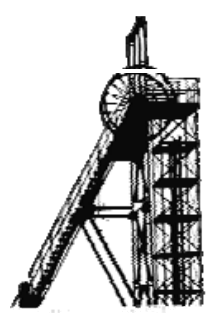

proporciona Pepe Cros, hijo de Pencho Cros, tres veces ganador del premio de cante por mineras en el Festival, la Lámpara Minera) como premiadas este año junto con la letra anterior:

\author{
Livianas de Lucena \\ son las que canto \\ cuando salgo de Ronda \\ pasito a paso.
}

Las tórtolas despiertan por el camino y las cigüeñas duermen a pie cojito.

He domao a mi potro, tú me conoces.

Ahora parece otro, no pega coces.

Come en mi mano: milagros de la vara del avellano.

1989

El premio de mineras queda desierto, y el de otras letras se menciona en las Crónicas que corresponde a Juan Francisco Aranda, lo que es un error, siendo el ganador Juan Francisco Arana Rupelo (Burgos 1944), que ganará otros premios de letras no mineras en el Festival en 1991 y 2001. Las letras ganadoras son unas seguiriyas. Las que se incluyen en las Crónicas y en el acta del jurado son:

Maldita la pluma,

maldito el papel,

y el cartero que trajo la carta

maldito también.

Desde mi ventana,

te he visto pasar.

Como sabía los caminos que andabas,

no te he dicho ná.

Pero en el documento original que el autor envió al concurso la letra continúa: 


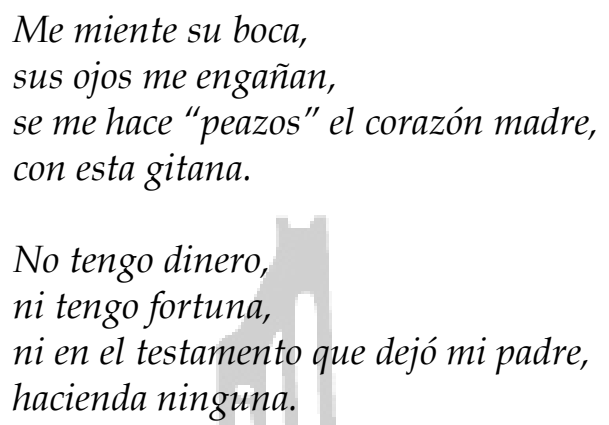

En el diario La Opinión de 19 de agosto se indica que el premio recoge dos seguiriyas de las varias presentadas por el autor, por lo que puede que en algunos casos el jurado decidiera mencionar en el acta de clasificación no una letra completa sino una parte que consideraba de mayor valor.

1992

Este año el premio de letras mineras se repartió en dos accésits para los dos autores más prolíficos, Jacobo Meléndez Martínez y Enrique HernándezLuike. En las Crónicas se indica que el ganador del de otras letras es Francisco Godella, lo que es un error, pues en realidad es Francisco Gadella Señorón, más conocido como Curro Gadella (Olivenza, Badajoz 1943; residente en Badalona).

Las Crónicas no incluyen las mineras premiadas, pero las encontramos en el acta de calificación del jurado. La letra de Jacobo Meléndez es:

En la sombra se perdía tu corazón, compañero.

Dime por qué galería puede encontrar un minero el metal de la alegría.

Y la de Enrique Hernández-Luike es una popular minera que aparece recurrentemente cuando se consulta información sobre el flamenco en La Unión:

Hay un Rey de las Mineras, rey por la gracia de Dios.

Cuando se acuñen monedas con perfil de Pencho Cros, compra todas las que puedas.

Las letras de otros cantes con las que ganó Curro Gadella fueron unas 
alegrías, que encontramos también en el acta del jurado:

$$
\begin{aligned}
& \text { Hay que ver como llovía } \\
& \text { la noche del aguacero } \\
& \text { hay que ver como llovía } \\
& \text { y tú moviendo el brasero } \\
& \text { cuando más agua caía... } \\
& \text { Fui tuyo y tú fuiste mía } \\
& \text { y cuando el día amaneció } \\
& \text { solo la noche sabía } \\
& \text { que pasó lo que pasó (bis) } \\
& \text { lo que tenía que pasar } \\
& \text { que el brasero se apagó } \\
& \text { y pelillos a la mar. } \\
& \text { Temporales del querer } \\
& \text { temporales, temporales } \\
& \text { temporales del querer } \\
& \text { corren llenos los canales } \\
& \text { cuando se pone a llover. }
\end{aligned}
$$

Aunque el autor nos indica que faltan los versos finales. De nuevo, no sabemos si el jurado decidió incluir en el acta sólo la parte de la letra que consideraba de más calidad. En cualquier caso, a continuación van las estrofas finales:

Te quitaste el mandil (bis) no sé que más te quitaste porque se apagó el candil.

Anda y no le soples más, sopla que sopla soplando. anda y no le soples más, se está el brasero apagando será de tanto soplar.

Calentitos en tu cama suspiros vienen y van y nos cogió la mañana Tirititi...ti...ti...tran...

1993

El premio “Andrés Cegarra Salcedo" va de nuevo a Jacobo Meléndez Martínez, y el de otras letras lo gana Francisco Acosta Roldán (La Calzada, 
Málaga 1935), que recibe el premio de mineras en 1994 y 1999, y el de otras letras en 1993 y 1995.

Aunque en las Crónicas se dice que la minera ganadora es la siguiente:

Si la mina es mi condena, no me indultan, compañero.

Nadie arranca de la mena

del corazón del minero

el mineral de la pena.

en el acta de calificación vemos que el jurado decidió repartir el premio entre dos mineras, pero que una vez abiertas las plicas resultaron ser las dos del mismo autor. La segunda de las letras es:

Si es de noche o si es de día, lo sabrán allí en la altura; yo sé que en la galería el metal de la amargura es mi sola compañía.

La letra premiada de Francisco Acosta correspondía a una colección de soleares. En las Crónicas se indica que era una larga composición, por lo que solo se mostraban algunos de los versos (del cuarto al sexto de los mostrados a continuación), pero en el acta del jurado la encontramos completa:

¿A quién le puede importar que mi pena, por el río

llegue o no llegue a la mar?

Nacimos tan diferentes que lo que a mí me da pena es lo que a ti te divierte.

No nos hemos entendio: yo estoy quieto como el puente y tú corres como el río.

Qué poquito me ha servío to lo que te he perdonao: por una vez que tropiezo iqué pronto me has condenao! 


\section{4}

En las Crónicas se dice que este año Francisco Acosta Roldán recibe el premio de letras de mineras, mientras que el de otras letras va al sevillano José Cenizo Jiménez. Se dan los mismos ganadores en 1999, en ese caso sin incluir las letras. José Cenizo nos confirma en comunicación personal que él ganó únicamente en 1999. Además, en la prensa comprobamos que los ganadores de los premios de letras en 1994 son Francisco Acosta Roldán del de mineras, y Francisco Almagro Herrera (Pegalajar, Jaén 1911-2007) del de otras letras, premio que también ganó en 1982.

Consultada la información del jurado en esta edición, no localizamos el acta de calificación, pero sí las letras enviadas por los ganadores, con una de cada uno resaltada, que suponemos que son por las que reciben el premio.

La minera de Francisco Acosta Roldán es:

$$
\begin{aligned}
& \text { Porque el miedo me da sed } \\
& \text { bebiendo yo mato el miedo } \\
& \text { porque el miedo me da sed; } \\
& \text { déjame beber, que luego } \\
& \text { bajo a la mina y no sé } \\
& \text { si podré subir de nuevo. }
\end{aligned}
$$

Y Francisco Almagro Herrera gana con las siguientes seguiriyas que titula "Mis cantares":

Me vió que llegaba,

la puerta cerró;

y aunque llamaba, llamaba y llamaba,

no me contestó.

Un montón de veces,

yo te he remediao;

hoy necesito que tú me remedies,

y me das de lao.

La vi que llegaba,

la puerta cerré;

y aunque llamaba, llamaba y llamaba,

no le contesté.

Mi corazón es sincero, 
cuando quise no quisiste, $y$ ahora, que quieres, no quiero.

1995

Los ganadores de esta edición repiten. El cordobés Jacobo Meléndez Martínez vuelve a ganar el premio "Andrés Cegarra Salcedo", y el malagueño Francisco Acosta Roldán el "Tertulia Literaria Mesa-Café".

Francisco Acosta ganó con las siguientes soleares, que aparecen en las Crónicas y se publicaron en la prensa sin la segunda, que sí se incluye en el programa del Festival de 1996:

Mi Triana de Alcalá.

¿Qué me importa a mí quién cante si canta por soleá?

Panaderos de Alcalá, alfareros de Triana y en medio, la soleá.

¿Quién pudiera levantar un puente de soleares de Triana hasta Alcalá!

\section{6}

Este año gana el premio de letras de mineras la primera (y a la postre la única) mujer galardonada, la unionense Paloma Celdrán Montoro (La Unión 1975-Madrid 2013). El premio de otras letras correspondió a Luis Antonio Utrera Madroñero (Málaga 1936), ganador del mismo premio también en los dos años siguientes, y que este año lo recibe por unas alboreás, de las que en las Crónicas se dice que se incluyen solo los primeros versos, y que encontramos completa en los documentos del jurado de letras (en el periódico La Opinión de 10 de agosto de 1996 se reproducen sin los ocho últimos versos):

En esta boda, padrino,

diga que no "farte ná",

ponga mantel y buen vino,

ique la novia es "coroná"!

Ya pasó la prueba 
con honra y con dolor, tres rosas, la novia en rojo dejó.

Vengan, parientes y amigos, que tengo la prueba ya, este pañuelo con nudos y tres rosas "colorás".

Al alba vengo a cantá, ofreciéndole a la novia mi canto de alboreá, pues ya ha salido en victoria.

Cantad, gitanos, cantad, que hay mucho que celebrar: ¡la novia salió ya en honra y el novio quiere bailar!

Los premios de este año fueron a parar a los mismos ganadores del año anterior: Paloma Celdrán Montoro el de mineras y Luis Antonio Utrera Madroñero el de letras de otros cantes, esta vez con unas bulerías.

La letra ganadora de Luis Antonio Utrera empieza en las Crónicas con tres puntos, lo que parece indicar que está incompleta. Nos lo confirma el autor, que nos proporciona los versos iniciales que aparecieron en algunos periódicos de Murcia y Almería como parte de la letra ganadora, que finalmente encontramos completa en el diario La Opinión de 14 de agosto de 1997:

Ende que tú más dejao no tengo caló en la fragua y el "jierro" se m'a enfriao.

Que quede esto entre los dos: tú eres gitana y no tienes ni sangre ni corazón.

Que yo vendo retales y mi gitana, en la feria manteles y delantares.

Tú no tienes compasión: en cada vez que yo te hablo 
me cambias conversación.

Las fatigas de la muerte paso yo, gitana mía, de está tan lejo y quererte.

S'a formao un alboroto y la probe de la Juana pagará los platos rotos.

¡Ni esto es cama, ni esto es ná! ar somié le faltan muelles y el relleno a la armoá.

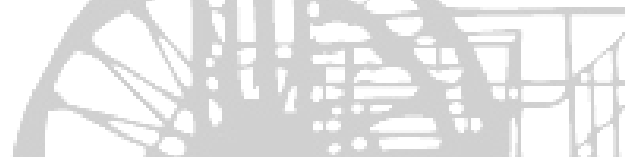

El premio de letras de mineras va al autor de este artículo, Domingo Giménez Cánovas (La Unión 1959), y el de otras letras por tercer año al malagueño Luis Antonio Utrera Madroñero, esta vez con unas malagueñas jaberas, de las que en las Crónicas aparecen dos, con una línea intermedia, lo que parece indicar que faltan algunos versos. En el periódico La Opinión encontramos tres malagueñas, que parecen componer la letra completa:

Por las calles y plazuelas los flamencos cantarán las malagueñas jaberas del barrio "La Triniá" que inventaron dos mozuelas.

Habas por Málaga entera en las calles pregonaban, se dice que eran mozuelas y vistosas y muy guapas las dos hermanas jaberas.

Ay, Virgen de la Victoria, Patrona de la ciudad, con Málaga en tu memoria por jabera y verdial estás cantando en la Gloria.

\section{9}

En las Crónicas se indica que Fernando Acosta Roldán es el ganador del 


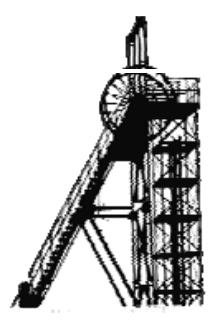

premio de letras mineras, y José Cenizo Jiménez (Sevilla 1961) del de otras letras. Los ganadores y las letras que se incluyen coinciden los que aparecen para 1994, con un error en el nombre de Francisco (no Fernando) Acosta. Consultando la prensa, comprobamos que los ganadores este año son Francisco Acosta Roldán y José Cenizo Jiménez, quien nos confirma personalmente que él recibió el premio únicamente en 1999. En consecuencia, las letras que en las Crónicas se repiten para 1994 y 1999 corresponden en realidad a 1999.

La minera ganadora de Francisco Acosta es:

$$
\begin{aligned}
& \text { Sin veta en su corazón } \\
& \text { aunque la mina se muera, } \\
& \text { cuidad siempre que el filón } \\
& \text { de los cantes por mineras } \\
& \text { no se le agote a La Unión. }
\end{aligned}
$$

De la letra de José Cenizo se muestran en las Crónicas únicamente cuatro versos (a partir de "Pobrecito"), pero en internet encontramos la que parece ser la composición completa ${ }^{1}$ :

\section{0}

Ya llega la nochecita con su negra soledad, con esta soguita al cuello cuándo me amanecerá.

Pobrecito del que llora sin que nadie lo consuele; con tener que llorar solo ya bastante pena tiene.

Las espinas del querer se alimentan de tu nombre por si lo quieres saber.

El premio de letras de mineras lo gana el trovero (él se llamaba trovador) Antonio Sánchez Marín (Doña Inés, Lorca 1949-San Pedro del Pinatar, Murcia

1 Disponible en https://www.experienceflamenco.com/blog/2013/09/night-is-on-its-wayviernes-con-una-letra. 
2011) y el de otras letras Alonso Palacios Rozalén (Salobre, Albacete 1952).

Alonso Palacios gana con unas serranas, de las que en las Crónicas se incluyen solo las dos primeras estrofas:

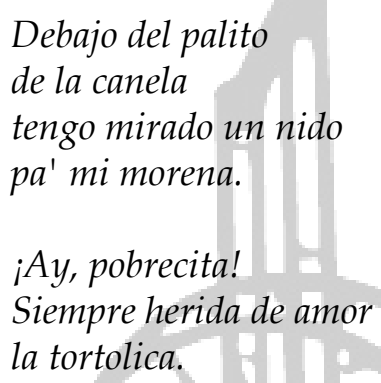

Pero encontramos dos estrofas adicionales en el acta del jurado:

Qué le habrán hecho, madre,

a las ortigas

que devuelven veneno

a las caricias.

Míralos en el agua

qué caballeros

los peces con sus trajes

de marineros.

\section{1}

El premio a la letra de mineras va al popular trovero Joaquín Sánchez Sánchez, “El Palmesano” (La Palma, Cartagena 1953), y el de otras letras a Juan Francisco Arana Rupelo, quien además gana este año también el premio del concurso de prosa.

No aparece en las Crónicas la letra de la minera premiada, pero nos la proporciona su autor:

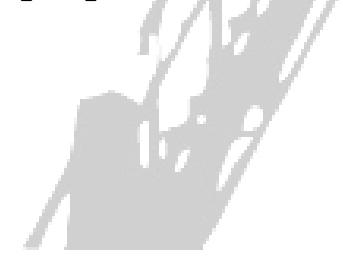

Que hayan cerrado el filón

al minero no le ofende porque el cante es la oración que mantiene vivo al duende de la sierra de La Unión.

Tampoco se incluye la letra de otros cantes, pero Paco Arana nos la proporciona, y corresponde a unas soleares: 
Sembré un olivo soñando olivar de mi consuelo, y cuando llegó el invierno la noche me trajo el hielo.

A mí se me importa poco que no llueva en los olivos, si se fue mi aceitunera $y$ desde entonces no vivo.

A mí qué me va a importar si se fue mi aceitunera que se seque el olivar.

La noche de la aceituna lloré por los olivares, mis penas una por una.

Todos mis olivos diera porque volviera conmigo de nuevo mi aceitunera.

A pesar de que en las Crónicas sólo aparecen referencias a premios de letras hasta la edición de 2002, hemos encontrado en el periódico El País del 18 de agosto de 2003 los galardonados de esta edición. El de mineras correspondió a Antonio Rincón Muñiz (Los Palacios, Sevilla), que ya ganó el de otras letras el año anterior, premio que este año va a Francisco Urrutia Fernández (Almería 1945-2015).

La minera ganadora fue:

Media vida en la mina mano a mano con la muerte, la otra media en la cantina renegando de mi suerte que me trajo a esta ruina.

Y Francisco Urrutia ganó con las siguientes bulerías:

De los Atochares se escapa la alondra por los olivares.

Yo bebí de tus manos 
agua del río,

$y$ entre redes de amores

quedé prendío.

Este amor recién nacío en la cuna de tus manos tengo que verlo crecío.

Entre las hojas verdes de un olivico brotan lágrimas negras por Federico.

2004

Encontramos en el blog de José Francisco López (Arahal, Sevilla 1963) sobre Flamenco y Literatura (flamencoyliteratura.blogspot.com) que ganó el premio de otras letras del Festival en 2004 con unas soleares, que él mismo nos proporciona. En conversación personal nos confirma que ese año el premio de mineras quedó desierto.

Las soleares premiadas son:

Esa gitana que baila alrededor de la hoguera tiene su cuerpo bañado de fuego y de luna llena.

Toca el cielo con las manos y un manojito de estrellas le regala a los flamencos bailando por peteneras.

Tienen tus labios, serrana, la piel del melocotón y el color de la granada.

Quiero quemarme en el fuego que desprende tu mirar y que las llamas me abrasen cantando por soleá.

Al margen de los premios de letras, el Festival propicia ocasionalmente de diversas formas la creación de nuevas letras. Así, en las bases del concurso de cante de esta edición se establece un suplemento de 150 euros a cada premio del 


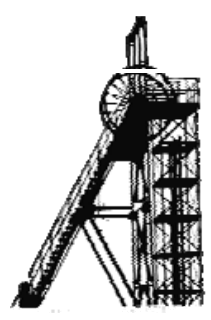

grupo primero (mineras, cartageneras, tarantas, murcianas y otros cantes mineros) por la interpretación de nuevas letras.

\section{Resumen de datos y trabajos adicionales}

Las búsquedas realizadas en bibliografía y prensa, las consultas directas a algunos de los autores de las letras premiadas, y el acceso a algunas de las actas de los jurados calificadores, han hecho posible completar toda la información sobre los ganadores y las letras, que era el objetivo principal de este trabajo.

Se han localizado o completado un total de 24 letras de las 70 galardonadas en todas las ediciones y modalidades, lo que hace un total de aproximadamente un $34 \%$, con un $17 \%$ de nuevas incorporaciones en el caso de las mineras (6 de 34$)$ y de un $50 \%$ en otras letras (18 de 36$)$.

Este trabajo forma parte de otro más ambicioso en el que pretendemos incluir, además de los autores y letras, otra información suplementaria sobre los premios de letras (patrocinadores, jurados, cuantía, actividades literarias en el marco del Festival, etc.) y también sobre los galardonados (fotografías, información biográfica y bibliográfica, referencias y letras o poemas adicionales a los galardonados en el Festival). Por las condiciones en que se ha realizado la búsqueda, con restricciones en el acceso a recursos de los archivos y bibliotecas como consecuencia de la pandemia por el coronavirus, y con el archivo de La Unión cerrado, no ha sido posible completar toda la información deseada.

Comentamos los distintos datos por completar:

- Sería deseable tener las actas de calificación de los jurados en todas las ediciones, pero por ahora se ha tenido acceso solo a algunas de ellas: 1971, 1972, 1973, 1975, 1979, 1987, 1988, 1989, 1990, 1992, 1993 y 2000. De todas formas, tal como hemos indicado, algunas veces no se incluye en el acta de clasificación las letras completas remitidas por los autores. 
- A través de la prensa y de las Crónicas tenemos información de los componentes del jurado de letras algunos años, y en las ediciones de 1971 a 1973 tenemos la composición del jurado de cante, que es también el de letras, ya que en estas ediciones había un único premio de letras, el correspondiente a letras inéditas interpretadas en el festival. Los jurados de los que no conocemos sus miembros son los de las ediciones de 1974, 1978, 1980, 1981, 1982, 1997, 1998, 2001, 2002 y 2004.

- En lo que se refiere a las cuantías, no conocemos las de 1999 y 2004 del premio de otras letras.

Una vez completada toda esta información pensaremos en la mejor manera para su difusión. Por lo pronto, un resumen se está incluyendo en el blog premiosletrascanteminas.blogspot.com.

Se agradece la comunicación de errores, información complementaria, propuesta de modificaciones, aclaración de datos, sugerencias, etc., lo que se puede hacer a través del correo domingo@um.es.

\section{Agradecimientos}

Agradezco a los autores Francisco Acosta Roldán, Juan Francisco Arana Rupelo, José Cenizo Jiménez, Francisco Gadella Señorón, Enrique HernándezLuike, José Francisco López, Alonso Palacios Rozalén, Joaquín Sánchez “El Palmesano" y Luis Antonio Utrera Madroñero, a los que contacté por correo o teléfono y que me atendieron gustosamente, que proporcionaran amablemente cuando les fue posible la información y las letras que les solicité.

Agradecimientos también a las personas que me facilitaron el contacto con los autores anteriores o información sobre ellos: Andrés García García, Concejal de Cultura de Alhaurín de la Torre, me puso en contacto con Francisco Acosta Roldán; alguien de la Tertulia Flamenca de Badalona (a quien accedí a través de mi hijo, de su amigo Edu de Badalona y del suegro de este) me puso en contacto 


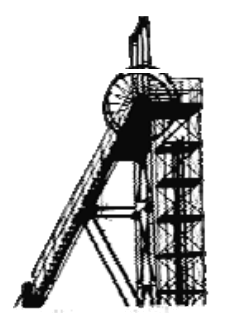

con Curro Gadella; Helena Hernández con su padre, Enrique Hernández-Luike; Marco, de la "Peña Flamenca Niña de Los Peines", de Arahal, con José Francisco López; la esposa de Jacobo Melénez, que me informó de su muerte el 25 de enero de 2020 y me autorizó para utilizar algunas de sus letras enviadas a los concursos del Festival; alguien del CEIP Micaela Sanz de Archena, me facilitó contactar con Alonso Palacios Rozalén; el presidente de la Asociación Trovera “José María Marín” con “El Palmesano”; y alguien de la Peña Flamenca Juan Breva y la letrista malagueña Carmen Aguirre me pusieron en contacto con Luis Antonio Utrera.

$\mathrm{Y}$ a otras personas que me han proporcionado contactos e información, o me facilitaron el acceso a ellos: Pepe Cros, con el que tuve algunas conversaciones muy clarificadoras y que me facilitó numerosos contactos e información; Miguel Zamora, que me facilitó la consulta de documentos de los jurados de letras en algunas ediciones y que me ayudó en la consulta junto con Pepe Cros; Salvador, del ayuntamiento de La Unión, que me franquea ocasionalmente la entrada al archivo de la ciudad; y Pedro López Millán, alcalde de La Unión, que autorizó esas consultas.

Y a mi mujer, Mari Trini Cámara, por su ayuda con el editor de texto y en la búsqueda en internet de algunos datos complementarios.

\section{Bibliografía}

Blanco GarzA, José Luis, RodRíGuez OJEDA, José Luis y ROBLES RODRÍGuEZ, Francisco, (2004). Las Letras del Cante Flamenco. Sevilla: Signatura.

Festival NAcional Del CAnte De las Minas (1991). Memoria. La Unión: Ayuntamiento de La Unión [consultada en la Biblioteca Regional de Murcia].

HERNÁNDEZ-LuIKE, Enrique, (2015). Coplas para cante flamenco, segunda versión de la Carpeta de Pencho Cros. Madrid: Fundación Luike.

MARTínez HernándeZ, José, (2005). El cante flamenco. Córdoba: Almuzara.

Ortega Castejón, José Francisco, (2017). Cantes de las minas, cantes por tarantas. Murcia: Editum. 
Ortega Castejón, José Francisco, Soler Guevara, Luis, Ruiz García, Rafael y Gómez Alarcón, Antonio. (2019). Malagueñas, creadores y estilos. MurciaMálaga: Editum-UMA Editorial.

SÁez García, Asensio y Pérez SÁnchez, José Alfonso, (2010). Crónicas del Festinal Internacional del Cante de las Minas. Murcia: Excmo. Ayuntamiento de La Unión.

UTRERA MADROÑERO, Luis Antonio, (1995). El arte flamenco, legado de Andalucía. Letras flamencas. Isla de Arriarán, revista cultural y científica, n. 6, pp. 325-334. (Disponible en https:// dialnet.unirioja.es/servlet/articulo?codigo=2709411).

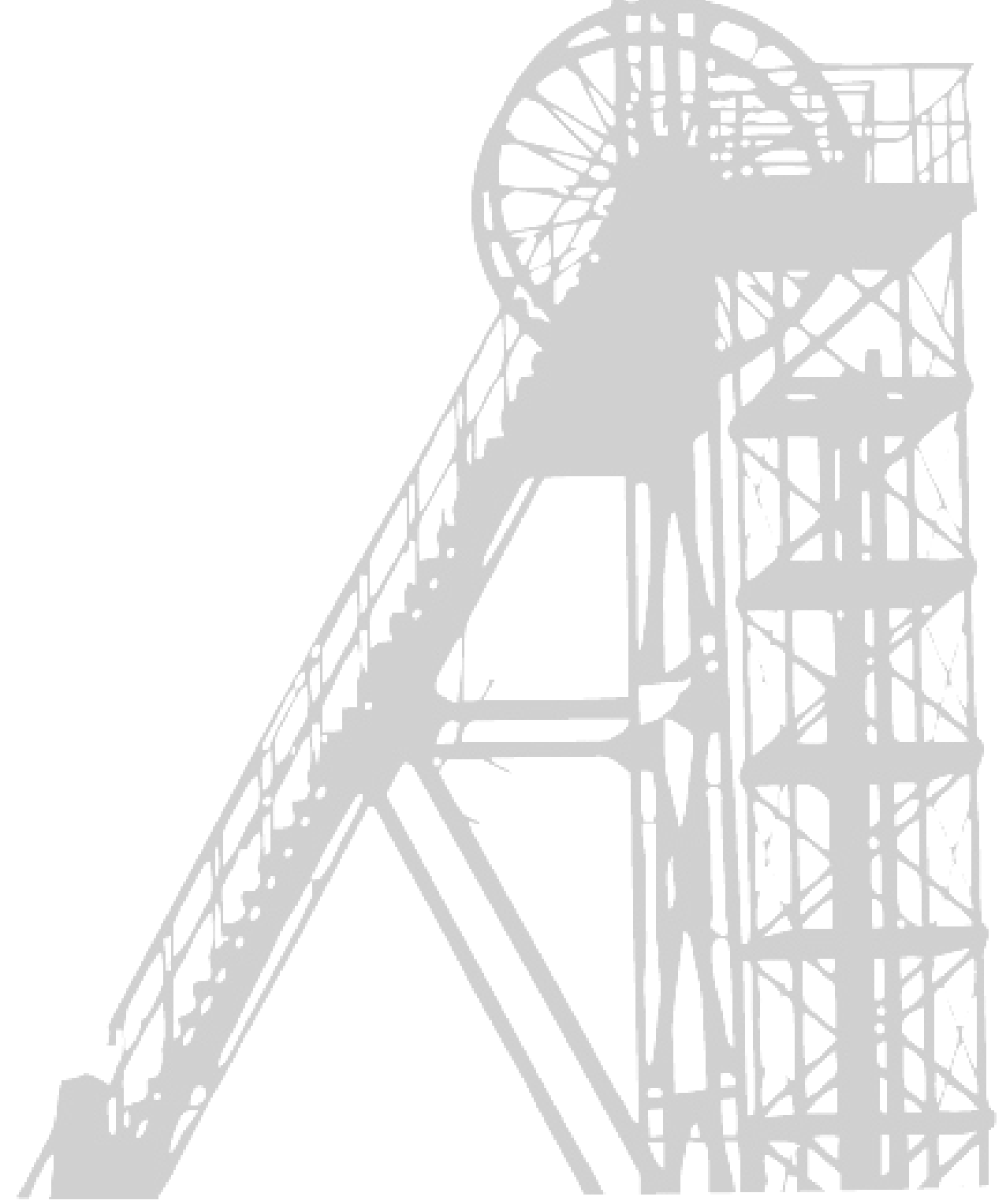

